não é sobre essas coisas miúdas ou medianas, mas sobre opções extremas: reconstrução total ou destruição total, "socialismo ou barbárie". Do contrário, a realidade profunda não poderia ficar tão clara para todos, como o próprio revolucionário o exige. Contudo, em vez de ficar agourando a destruição, Boito Jr. prefere anunciar que, depois de tantas desgraças se abaterem sobre os explorados e os injustiçados, haverá de surgir a oportunidade do grande acerto de contas que exterminará o sistema causador de tais desgraças: é isso o que significa o socialismo, não importa o que venha a ser efetivamente. Mas isso também significa que não estamos mais exatamente na ordem de uma previsão racional, feita para concordar ou discordar. $\mathrm{O}$ registro é outro: em seu estilo tranqüilo e discreto, Armando Boito Jr. oferece-nos na verdade um grande alento, uma mensagem de alta esperança. E assim ficamos com um desconcerto final: podemos desconfiar da mensagem, mas ela já está para além da crítica.

CICERO ARAUJO

é professor do Departamento de Ciência Política da FFLCH/USP. E-mail: craraujo@usp.br.

\section{Do privado ao público na política brasileira}

Moacyr PALMEIRA e César BARREIRA (orgs.). Política no Brasil: visões de antropólogos. Rio de Janeiro, Relume Dumará, 2006. 449 páginas.

\section{Celi Regina Jardim Pinto}

Uma coletânea é sempre muito bem-vinda, mas muitas vezes nos defrontamos com uma coleção de textos que, independentemente da qualidade de seus autores, não constitui um todo que conduz ao diálogo intertextual.

Característica de uma boa coletânea é, portanto, a unidade organizadora no que pese seus inúmeros temas. Politica no Brasil: visões de antropólogos, livro corajoso, composto em 449 páginas, cinco partes e dezoito capítulos, atinge com eficiência as premissas de uma boa coletânea. Com uma formidável unidade, o leitor vislumbra o olhar que norteia a totalidade dos artigos, sem que seja preciso explicitar a cada página as teorias metodológicas do trabalho. Nota-se claramente um grupo de pesquisadores articulados, pensando juntos. Apesar da diversidade temática, os textos dialogam entre si, mostrando como a vida política no país é construída pelas relações estabelecidas no espaço público da política. A idéia é analisar de que maneira a esfera pública mantém relação com o mundo privado e o quanto os compromissos entre essas esferas se confundem, seja entre as famílias, seja no processo constitutivo de carreiras políticas, em que se explicitam a procura e o encontro de eleitores.

Os indivíduos, as relações de poder, a questão de classe, do privado e da trama não expressada nas instituições, mas que chega a elas já formatadas em cargos públicos, são, para os autores, aspectos relevantes a serem tratados nos estudos sobre a política. É importante, pois, que se analise toda a rede de relações que envolve a questão política sob a superfície codificada das instituições políticas.

O livro como um todo induz a uma leitura linear, pois a partir de questões gerais, levantadas na primeira parte, "Democracia, justiça e cidadania", chega-se a questões bem especificas, analisadas na última parte, intitulada "Eventos e politização das relações sociais". Esta trajetória garante à coletânea 
o desenvolvimento da obra com início, meio e fim, mesmo que não exista, na realidade, tal seqüência.

O cidadão de direito em face do aparato estatal é o tema central do início do livro. Mariza Peirano discute a importância do documento de identidade no imaginário do brasileiro. Seu exemplo é paradigmático e faz parte da vida de todos nós: "O apelo para que os ladrões devolvam os documentos é uma constante no Brasil, já que eles são geralmente guardados na mesma carteira que o dinheiro: depois de assaltado no Rio de Janeiro, bem humorado Ronaldinho pediu na televisão aos assaltantes - Devolvam pelo menos os meus documentos" (p. 27). Luis Roberto Cardoso de Oliveira leva mais longe a questão da cidadania, comparando o Brasil a Québec, não só sob o aspecto legal, mas também sob a questão ético-moral. Domingos Abreu toma uma questão específica para falar de cidadania, mas de grande atualidade e importância: a lei de adoção por brasileiros e estrangeiros. O autor faz uma verdadeira arqueologia nos trâmites da lei para chegar ao ECA (Estatuto da Criança e do Adolescente). Por fim, Rosemary de Oliveira Almeida discute a relação entre o Judiciário e as mulheres assassinas, analisando como cada operador neste cenário representa o outro e a si mesmo. O texto é muito sagaz em mostrar que até mesmo no mundo jurídico da contravenção a mulher é invisível. Ela não se reconhece como criminosa, e o próprio aparato jurídico também não o faz, a não ser que se trate de prostitutas ou lésbicas: "O não lugar da mulher assassina parece ser construído pela representação da emoção com a instituição cultural da mulher dependente do homem, submissa, frágil, dócil e maternal” (p. 121).

O foco da segunda parte do livro, "Poder, política e facções", é a luta entre facções, em que o limite entre o legal e a contravenção é muito tênue. Os capítulos tomam a política local como um espaço privilegiado da vida política brasileira. Moacyr Palmeira traça com muita finura o mundo político do interior brasileiro. Cita o caso de um prefeito do interior de Pernambuco que, desejando racionalizar sua administração, concentrou toda a área de assistência social em uma só Secretaria, para qual foi nomeada sua própria esposa. No final do mandato, a "voz do povo" dizia que ela era a verdadeira prefeita, tendo sido inclusive eleita para suceder o marido (p. 145).

César Barreira analisa fraudes e corrupções nas eleições do Ceará com dados de sua pesquisa no município de Canindé, situando essa questão no universo político do país ao longo de sua história. É particularmente fecunda a análise da relação entre corruptor e corrompido. Sobre o tema conclui: "A relação eleitor-candidato, ou entre corruptíveis e corruptores, é gestada no interior da relação patrão-cliente, dos benfeitores e do compadrio. Esse contexto sociopolítico tanto dificulta o discernimento entre o voto comprado, voto por gratidão e voto consciente como situa no centro das discussões o clientelismo e a patronagem" (p. 162).

A eleição municipal é vista por outro prisma por Beatriz Herédia, que estuda a disputa entre facções e intrafacções: "A disputa com os candidatos da outra facção é uma disputa que tem lugar durante a campanha eleitoral e, geralmente, restringese a ela. Dentro da facção, ao contrário, a disputa pelo espaço é uma disputa constante. Isso indica a existência de uma temporalidade específica para os políticos" (p. 175)

Marcos Bezerra dá continuidade ao exame da política municipal com um capítulo de título sugestivo "Caminho das Pedras", em que analisa a rede de relações que permite a política local chegar até os detentores dos recursos econômicos, o poder federal. O autor observa: "O interesse na obtenção dos recursos federais acaba numa espécie de círculo vicioso, fortalecendo os parlamentares considerados 'fortes'. $\mathrm{Na}$ frase de um ex-prefeito: tem que procurar um deputado forte para hipotecar apoio e depois trazer o retorno. Sua maior capacidade de conceder esta forma de benefício, disputado pelas lideranças locais, acaba favorecendo a consolidação de compromissos que são convertidos em apoio políticas nos municípios" (p. 195

Esta segunda parte é fechada com um artigo bastante especifico de Marcio Goldman sobre a política do ponto de vista do Movimento Negro de Ilhéus. $\mathrm{O}$ autor descreve as diversas lógicas presentes em um momento eleitoral dentro e fora do movimento negro. É interessante nesse sentido a diversidade do movimento e a forma pela qual suas diferentes manifestações se relacionam com a política.

Composta de três artigos, a terceira parte da coletânea examina a trajetória de políticos. Julia Miranda e Maria Auxiliadora Lemenhen analisam, respectivamente, a vida política de dois médicos, Mão Santa, no Piauí, e Dr. Feitosa, em Juazeiro do Norte no Ceará. As coincidências entre essas duas carreiras levam à discussão de um tema central no 
âmbito dos estudos políticos, qual seja, as formas de relacionamento do eleitor com a política e com os políticos. Segundo Miranda, "através de um particular e permanente contato com os segmentos mais pobres do estado, ele [Mão Santa] foi construindo uma mística de protetor 'do povo', identificando de modo explícito e com alusão a seu nome e data de nascimento - 4 de outubro - sua prática a de São Francisco de Assis" (p. 233). Lemenhen, por sua vez, com base na trajetória de Dr. Feitosa, chega a conclusões semelhantes: "O médico caridoso se veste também de homem político dotado de virtudes extraordinárias, dotado de poder de fazer milagres ou de exercer a função de intermediário entre o poder santificado e os crédulos em dificuldade" (p. 255).

Com uma argumentação distinta, Coradini, em um longo artigo, defende a hipótese de que a relação entre profissão e trajetória política não tem referentes teóricos e empíricos que a sustente: "este artigo vai no sentido contrário [do senso comum], visto que a idéia básica é a de que, por mais que haja uma super-representação de determinadas profissões na esfera política, não existe alguma continuidade, visto que se trata de esferas com lógicas distintas" (p. 266).

A parte que se segue trata do tema "Família e política". Aqui, encontramos um capítulo sobre a Argentina que, a meu ver, foge aos objetivos da coletânea, uma vez que o próprio título da obra restringe a análise ao Brasil. O capítulo seguinte, de autoria de Irlys Barreira, constitui-se em um estudo aprofundado, na cidade de Acaraú, da disputa eleitoral intrafamiliar, depois do assassinato de um prefeito e da eleição de sua viúva. Comentando o projeto de reforma implantado pela prefeita, Barreira pontua: "A mudança de nome de ruas e monumentos, criados durante a gestão municipal dos parentes acusados do crime, integrou também os projetos de reforma urbana empreendidos pela administração municipal da viúva. Tudo se passa como se a história da família e o enredo político do município fossem recontados, tornando indissociáveis, no presente, a família, a política e a cidade" (p. 317). Vale notar neste artigo a importante discussão sobre gênero que a autora introduz ao examinar a campanha e a eleição da prefeita.

Por outro lado, Ana Cláudia Marques mostra como duas brigas entre famílias advindas de acontecimentos pueris acabam tomando dimensões muito maiores que implicam crimes e atentados. Contudo, os casos não estão diretamente ligados a disputas políticas, mas o interesse da autora centrase nos próprios conflitos: "importa-me vê-los em seu funcionamento, em sua articulação com toda a vida social" (p. 364).

O primeiro capítulo da quinta e última parte da coletânea - "Eventos e politização das relações sociais" - trata da audiência pública em Angra dos Reis, que ocorreu em 1999, sobre o licenciamento da usina nuclear Angra 2. Os autores José Sérgio Leite Lopes, Diana Antonaz, Gláucia Oliveira e Rosane Prado descrevem com muito rigor o impacto causado pela discussão de um tema tão controverso, que contemplou defensores e opositores contundentes e muito bem organizados. Uma das conclusões dos autores sobre esta audiência é particularmente interessante: "ainda é muito cedo para fazer um balanço de eventuais ganhos da população local decorrentes da audiência pública. O que se pode registrar, no entanto, é que, por algum tempo, os participantes conseguiram colocar a estrada e as medidas compensatórias no centro da discussão; a empresa tendo de dar atenção a temas acessíveis à sensibilidade (e ao bom senso) do saber popular (mesmo que amparado pelo saber técnico dos dispositivos práticos do plano de emergência), e colocando em pé de igualdade o saber técnico atômico mais sofisticado" (p. 388).

Gabriela Scotto contribui com o exame do marketing político no cenário eleitoral. Trata-se de um texto descritivo que estudo principalmente o trabalho que constrói a imagem dos políticos. Carla Costa Teixeira, por seu turno, encerra a coletânea discutindo a nova lei de imprensa no Brasil (1996). O estudo mostra a relação entre os políticos e os jornalistas durante a tramitação desse projeto de lei. Tema bastante importante, na medida em que as marcas da censura e dos desmandos do regime militar ainda são muito presentes quando se trata de qualquer tipo de regulamentação no campo da comunicação e da cultura: $\mathrm{O}$ autor pontua: "a questão que a polêmica da lei de imprensa permite ver é a dificuldade de especificar e disciplinar a responsabilidade quando se trata de profissionais da imprensa, pois se vivem muitas vezes da e para a política, contudo não são sujeitos diretos da ação política constitucional" (p. 432).

Em suma, Politica no Brasil: visões de antropólogos percorre uma vasta gama de importantes temas de 
pesquisa. Sua contribuição é particularmente marcante no estudo das relações entre os setores público e o privado na política brasileira, questão sempre atual no país.

\section{CELI REGINA JARDIM PINTO é doutora em Ciência Política na University of Essex, UK, diretora do IFCH na Universidade Federal do Rio Grande do Sul e professora do Programa de Pós-graduação em História da UFRGS. E-mail: celi.pinto@ufrgs.br}

\section{Em busca dos fundamentos: Auerbach como uma das fontes da crítica literária no Brasil}

Leopoldo WAIZBORT. A passagem do três ao $\mathrm{um}$. São Paulo, CosacNaify, 2007. 346 páginas.

Ronaldo Oliveira de Castro

O próprio título do livro de Leopoldo Waizbort indica uma forte relação com Antonio Candido. A Passagem do três ao um remete ao título de um artigo de Candido, "A passagem do dois ao três". Mas indicaria um caminho de volta, um retorno? Creio que sim, trata-se de uma tentativa de fazer um giro em direção aos pressupostos que não só orientam a crítica de Antonio Candido, que é de certa forma o tema central do livro, mas também revelam alguns fundamentos da crítica sociológica em dois outros autores nacionais, Raymundo Faoro e Roberto Schwarz. Mas se Candido é o centro, o ponto de partida e seu fio condutor é Erich Auerbach.

O livro está dividido em três partes: a primeira dedica-se à discussão de interpretações de Machado de Assis, a saber, os livros de Faoro, A pirâmide e o trapézio, e de Schwarz, Ao vencedor as batatas (ainda que a presença de Um mestre na periferia do capitalismo não seja insignificante); a segunda parte discute a trajetória crítica de Antonio Candido, e a terceira encerra o livro com uma reflexão sobre a crítica de Auerbach, que envolve filologia e sociologia.

O ponto de partida é Mimesis, no qual Auerbach apresenta uma complexa discussão sobre o realismo literário, que, em vez de ser definido de forma unívoca, é entendido como exposição da realidade. Auerbach persegue as múltiplas "feições" sob as quais a realidade pôde ser configurada na literatura européia, imprimindo no livro uma "dimensão aberta" que caracteriza um conjunto de fragmentos articulados entre si. Waizbort, por sua vez, propõe ampliar tal pluralidade, mostrando como outros esforços de pensar configurações realistas poderiam se encaixar na perspectiva aberta por Mimesis.

A partir daí, o autor anuncia a discussão que constitui a primeira parte do livro: como Faoro e Schwarz concebem o modo de exposição da realidade na literatura de Machado de Assis, mostrando como o texto literário e a realidade se relacio- 